\title{
Irregular structures of the F layer at high latitudes during ionospheric heating
}

\author{
E. D. Tereshchenko ${ }^{1}$, M. O. Kozlova ${ }^{1}$, O. V. Evstafiev $^{1}$, B. Z. Khudukon ${ }^{1}$, T. Nygrén ${ }^{2}$, M. Rietveld ${ }^{3}$, A. Brekke ${ }^{4}$ \\ ${ }^{1}$ Polar Geophysical Institute, 15 Khalturina, 183010 Murmansk, Russia \\ ${ }^{2}$ Department of Physical Sciences, University of Oulu, P.O. Box 3000 FIN-90401 Oulu, Finland \\ ${ }^{3}$ EISCAT, N-9027 Ramfjordbotn, Norway; also at Max-Planck-Institut für Aeronomie, D-37191 Katlenburg-Lindau, Germany \\ 4 Auroral Observatory, University of Troms $\varnothing$, N-9037 Troms $\varnothing$, Norway
}

Received: 14 January 2000 / Revised: 5 May 2000 / Accepted: 23 May 2000

\begin{abstract}
Results on heating the ionospheric F region above Troms $\varnothing$, Norway are presented. The ionosphere was monitored by satellite tomography and amplitude scintillation methods as well as the EISCAT incoherent scatter radar. No effect of heating was observed in the daytime. In the evening and in the pre-midnight sector, noticeable tilts of the $\mathrm{F}$ region were observed during heating periods. The tilts overlapped the heating cone, where the electron density decreased and irregularities exceeding $10 \mathrm{~km}$ in size appeared. Between the heating periods the $\mathrm{F}$ layer was restored to its horizontal shape. The anisotropic parameters of small-scale irregularities with scale lengths of hundreds of metres were also determined. It was found that the perpendicular anisotropy points in the direction of $F$ region plasma flow. In some cases the results can be explained by assuming that the small-scale irregularities were generated within the heating cone and drifted out of the heating region where they were subsequently observed.
\end{abstract}

Key words: Ionosphere (active experiments; auroral ionosphere; ionospheric irregularities)

\section{Introduction}

Modification of the ionosphere by HF radio waves is an efficient method of studying the physical processes in the ionosphere. When the ionosphere is affected by powerful radiation, fast heating of the plasma causes drastic changes in the energy distribution. The resulting instabilities can provide appropriate conditions for generation of artificial ionospheric irregularities. Previous investigations have shown that heating the ionosphere can produce electron density irregularities with scale sizes from tens of metres up to tens of kilometres (e.g.

Correspondence to: T. Nygrén
Basu et al., 1987; Costa et al., 1997; Tereshchenko et al., 1998). Investigating their structures helps deeper understanding of the physical processes controlling the ionospheric conditions.

Previous studies were mostly aimed at studying the effects of heating within a comparatively limited area over the heating facility. In addition to this, the spatial location and dynamics of the heated plasma cloud are also of great interest. The generation, the structure and the evolution of the artificial irregularities are strongly dependent on the natural conditions in the ionosphere. When investigating the heated ionosphere, it is therefore of great importance to know the state of electron density within a larger region both before and during heating periods. Ionospheric radiotomography is a powerful method capable of mapping the electron density within a large region at a temporal resolution of about an hour. Similar information is obtained by means of incoherent scatter radars, which can also be used for observing the $F$ region plasma drift.

Together with large-scale irregularities, small-scale inhomogeneities can also be generated under appropriate physical conditions. The parameters of small-scale irregularities can be investigated using a new method recently developed at the Polar Geophysical Institute in Murmansk, Russia (Tereshchenko et al., 1999, 2000). The method is based on the analysis of amplitude scintillation of satellite radiosignals.

In November 1997 an experiment on the ionospheric modification by powerful HF waves was carried out in northern Scandinavia. This work reports results of this experiment.

\section{Experimental setup}

During the heating experiment from 9 to 17 November, 1997, the ionosphere was investigated by means of radio tomography and the EISCAT UHF radar. Tomographic measurements were carried out at five receiving sites. The receiver chain was arranged approximately along the local geomagnetic meridian. Three satellite receivers 
were installed comparatively close to each other (spaced about $50 \mathrm{~km}$ apart) in the north of Norway at Kårvika $\left(69.87^{\circ} \mathrm{N}, 18.93^{\circ} \mathrm{E}\right)$, Troms $\varnothing\left(69.59^{\circ} \mathrm{N}, 19.22^{\circ} \mathrm{E}\right)$ and Nordkjosbotn $\left(69.22^{\circ} \mathrm{N}, 19.54^{\circ} \mathrm{E}\right)$. Measurements from these sites were used for tomographic reconstruction of electron density around the heating site. They also enabled us to investigate the parameters of small-scale irregularities using amplitude data. In addition, two remote tomographic receivers were installed in Sweden (Kiruna, $67.8^{\circ} \mathrm{N}, 20.4^{\circ} \mathrm{E}$ ) and Finland (Oulu, $65.0^{\circ} \mathrm{N}$, $25.49^{\circ} \mathrm{E}$ ) far away from the northern sites. Measurements from such an extended chain allows the determination of electron density within a large ionospheric region.

The receivers measured radio signals from Russian navigational satellites. The satellites fly at an altitude of about $1000 \mathrm{~km}$, the inclination of their orbits is $83^{\circ}$ and the orbital period is $105 \mathrm{~min}$. The receivers recorded the signals during about $18 \mathrm{~min}$ for each satellite pass ( \pm 9 min from the time of closest approach). Only data from satellites with highest elevations more than $80^{\circ}$ were used in the tomographic analysis. Southward passes of such satellites lie close to the geomagnetic meridian, which makes it possible to determine the electron density of the ionosphere in the vertical plane above the receiver chain. Northward satellite passes were not used in tomographic analysis because the paths are not parallel to the receiving chain.

The ionosphere was heated by powerful HF radiation transmitted from the EISCAT Heating Facility at Troms $\varnothing$. The facility was operated in $\mathrm{CW}$ mode. The radiation power was up to $1.08 \mathrm{MW}$ which, with an antenna gain of $24 \mathrm{dBi}$, results in an effective radiated power of $247 \mathrm{MW}$. The frequency was usually $4.04 \mathrm{MHz}$ (in several cases, which will not be analysed here, the frequency was 4.9128 and $4.544 \mathrm{MHz}$ ). The facility transmitted the radiation vertically for 10 or $15 \mathrm{~min}$ during selected passes of high-elevation satellites.

The EISCAT UHF radar with its transmitter and receiver at Troms $\varnothing$ (Norway, $69.59^{\circ} \mathrm{N}, 19.23^{\circ} \mathrm{E}$ ) and remote receivers at Sodankylä (Finland, $67.36^{\circ} \mathrm{N}$, $26.63^{\circ} \mathrm{E}$ ) and Kiruna (Sweden, $67.86^{\circ} \mathrm{N}, 20.44^{\circ} \mathrm{E}$ ) measured the electron density profile along the transmitter beam and the drift velocity vector in the $\mathrm{F}$ region. The experiment was basically similar to CP-1-K, which makes use of 16-bit alternating codes, short pulses and long pulses. It gives power profiles and autocorrelation functions for $\mathrm{E}$ region as well as coarse-resolution power profiles and conventional long-pulse autocorrelation functions for the $\mathrm{F}$ region. A special property of the present programme version was that the radar beam was not always stationary but its direction could be controlled by an external FORTRAN programme, simulating manual beam-positioning commands. This possibility was used to move the beam more or less in phase with satellites during their southward passes.

\section{Methods}

The radio tomographic and scintillation methods used in this work have already been described in several papers (Markkanen et al., 1995; Nygrén et al., 1997; Tereshchenko et al., 1999, 2000), and therefore we shall describe them only briefly here.

The large-scale ionospheric irregularities can be investigated by means of ray tomography. In this approach the measured phase of the probing radio signal is proportional to the total electron content (TEC) along the ray from the satellite radio source to the ground-based receivers, i.e.

$\phi \propto \int N_{e} \mathrm{~d} s$,

where $N_{e}$ is the electron density, $\mathrm{d} s$ is the ray element and $\phi$ is the phase. Multipoint phase measurements at different satellite positions provide a set of integrals along intersecting rays. Tomographic inversion of these data gives the electron density in a vertical plane above the receivers.

In contrast to the large-scale irregularities mostly contributing to phase fluctuations, the small-scale irregularities (from about hundreds of metres to kilometres) mainly affect the amplitude scintillation of radio signals. The parameters of small-scale irregularities can be determined from the amplitude data using the statistical method by Tereshchenko et al. (2000).

The theoretical part of the statistical scintillation method assumes that the ionosphere contains a layer of anisotropic small-scale irregularities. Their properties are described by the variance of electron density fluctuations $\sigma_{N}^{2}$, the field-aligned anisotropy parameter $\alpha$, the field-perpendicular anisotropy parameter $\beta$ and the orientation angle $\Psi$ of the anisotropy in the plane perpendicular to the geomagnetic field. The spectrum of the fluctuations is assumed to obey the power law with a power index $p$. Using the definition of the logarithmic relative amplitude $\chi=\ln \left(A / A_{0}\right)$, where $A_{0}$ is the amplitude in the absence of irregularities, it can then be shown that its variance is

$$
\sigma_{\chi}^{2} \propto \int_{z_{L}}^{z_{U}} \sigma_{N}^{2}(z) \cdot f\left[R_{F}(z), \alpha, \beta, \Psi, p, \Theta(z)\right] \mathrm{d} z .
$$

Here integration is carried out along the ray connecting the satellite and the receiver and the integration limits $z_{L}$ and $z_{U}$ are the lower and the upper boundaries of the layer of irregularities. The function $f$ is given by Tereshchenko et al. (2000) and depends on $\alpha, \beta, \Psi$ and $p$, as well as on the Fresnel radius $R_{F}$ and on $\Theta$, which is the angle between the geomagnetic field direction and the ray from the radio source to the receiver.

The logarithmic relative amplitude $\chi$ cannot be determined experimentally, since $A_{0}$ cannot be measured. Instead, the experimental part of the method is based on determining the variance of the quantity $\chi_{e}=\ln (A /\langle A\rangle)$, where $A$ is amplitude and $\langle A\rangle$ its mean value. It turns out that $\sigma_{\chi}^{2}=\sigma_{\chi_{e}}^{2}$ so that the experimental and theoretical variances can be directly compared. The amplitude of the satellite signal is sampled at a frequency of $50 \mathrm{~Hz}$ and the variance $\sigma_{\chi_{e}}^{2}$ is estimated from a sequence of 500 successive data points. A linear 
fit to these 500 data points is first made and, for each sampling time, the fitted value is taken as an estimate of $\langle A\rangle$. Then $\chi_{e}$ is computed for every sample in the data window and $\sigma_{\chi_{e}}^{2}$ is obtained as a variance of these values. The data window is shifted in steps of 50 points so that $\sigma_{\chi}^{2}$ is determined in steps of $1 \mathrm{~s}$.

Using Eq. (2), $\sigma_{\chi}^{2}$ can be calculated as a function of the satellite position for a given model of electron density fluctuations. In the simplest case of a statistically homogeneous layer, $\sigma_{\gamma}^{2}$ has a single maximum at some specific satellite position. The shape and the location of this peak depend on the parameters of the irregularities and the angle $\Theta$. Since $\sigma_{\chi}^{2}=\sigma_{\chi_{e}}^{2}$, it is possible to fit the theoretical curve of $\sigma_{\chi}^{2}$ to a peak in the experimental curve of $\sigma_{\chi_{e}}^{2}$. The anisotropy parameters $\alpha, \beta$ and $\Psi$ are obtained as a result of the best fit. Instead of $\Psi$, the orientation of the perpendicular anisotropy will be given later in terms of $\varphi$, which is the directional angle of the horizontal projection of perpendicular anisotropy axis, measured eastwards starting from geographic north.

The anisotropy parameters obtained from a single site describe the ionospheric conditions within a limited area in space (this will be called the spot of the measurement in rest of the study) and a limited time interval near the location of the peak. If the same parameters are obtained from several receiving sites, it seems that a statistically homogeneous layer of irregularities covers the space between the respective spots of measurements.

\section{Results}

The period of the observations turned out to be favourable for investigating artificial irregularities, because the natural ionosphere was regular at that time. This is indicated by quiet geomagnetic conditions during and just before the campaign (the $K p$ index was usually smaller than 3 , in a few cases close to 4 ). Only satellite passes with high elevations were used in the tomographic analysis, because the reconstruction of data from low elevation passes gives the sections of the electron density far away from the regions of the expected heating effects. It was also required that the phase and amplitude curves contain distinct scintillations indicating the presence of both large and small scale irregularities. Only comparatively few data from the whole campaign met these criteria.

The most complete experimental data set was obtained on 9 November, 1997. Ionospheric heating was carried out during five periods at 14:25-14:40, 15:0815:18, 17:46-18:01, 19:16-19:31 and 22:18-22:33 UT. Observations with high-elevation satellites were carried out during these periods. The start times of these satellite passes are 14:31, 15:09, 17:52, 19:21 and 22:23 UT. In addition, data from a satellite pass starting at 20:26 UT, occurring between two heating periods, were chosen for analysis. The projections of the satellite paths to $250-\mathrm{km}$ altitude, as seen from Troms $\varnothing$, are shown in Fig. 1 together with the locations of the three receiving sites and the location of the cone of maximum heating.

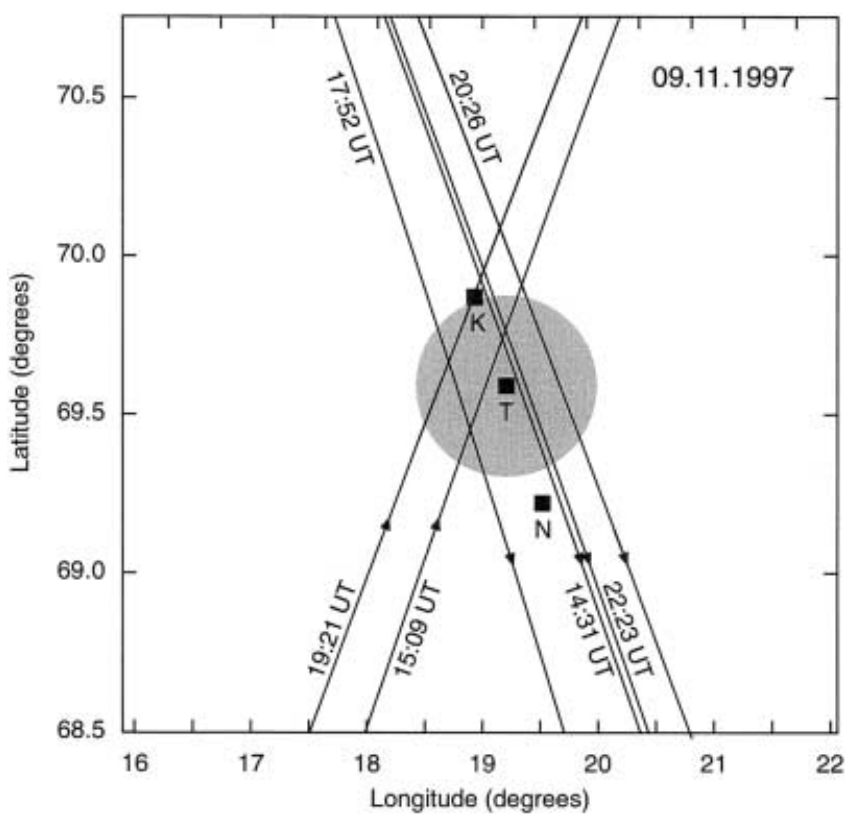

Fig. 1. The positions of the receiver sites Kårvika, Troms $\varnothing$ and Nordkjosbotn together with the projections of six satellite paths to $250-\mathrm{km}$ altitude as seen from Troms $\varnothing$. The times given are start times of registration. The flight directions of the satellites are indicated by arrows. The grey area shows the heating cone at a height of $250 \mathrm{~km}$ (boundary at $-3 \mathrm{~dB}$ )

All satellites fly through the heating cone. The directions of satellite motion are shown by arrows. Only data from southward passes are used in tomographic analysis.

The phase curves from Troms $\varnothing$ corresponding to these six satellite passes are shown in Fig. 2. The phase variation at 14:36:24-14:45:59 UT was close to a secant law curve, which means that the ionosphere was regular at that time. The phase curve at 15:13:11-15:21:45 UT was also quiet without any noticeable peaks. In both of these curves the phase increases southwards, which is typical of the daytime undisturbed ionosphere. The absence of phase disturbances indicates that heating had no large-scale effect on the ionosphere in these two cases.

Starting from 17:57:43-18:06:18 UT the phase curves alter considerably. The phase values decrease in the south, which is usual in the evening and night-time ionosphere with no solar illumination. The higher electron density in the north is produced by auroral precipitation. At latitudes from $67^{\circ} \mathrm{N}$ to $71^{\circ} \mathrm{N}$ the phase curves are no longer smooth, but distinct peaks are seen. The approximate latitude ranges of these peaks are shown by grey stripes in Fig. 2. Such phase variations indicate that large-scale irregularities were generated in the ionosphere at that time. In conclusion, the behaviour of the phases in Fig. 2 shows that both typical wide scale diurnal variations and more irregular comparatively local changes took place in the ionosphere. These changes are better visualised by means of tomographic analysis.

The tomographic reconstruction of electron density from the satellite pass at 14:31-14:49 UT is shown in Fig. 3, were the white lines outline the sector of maximal 

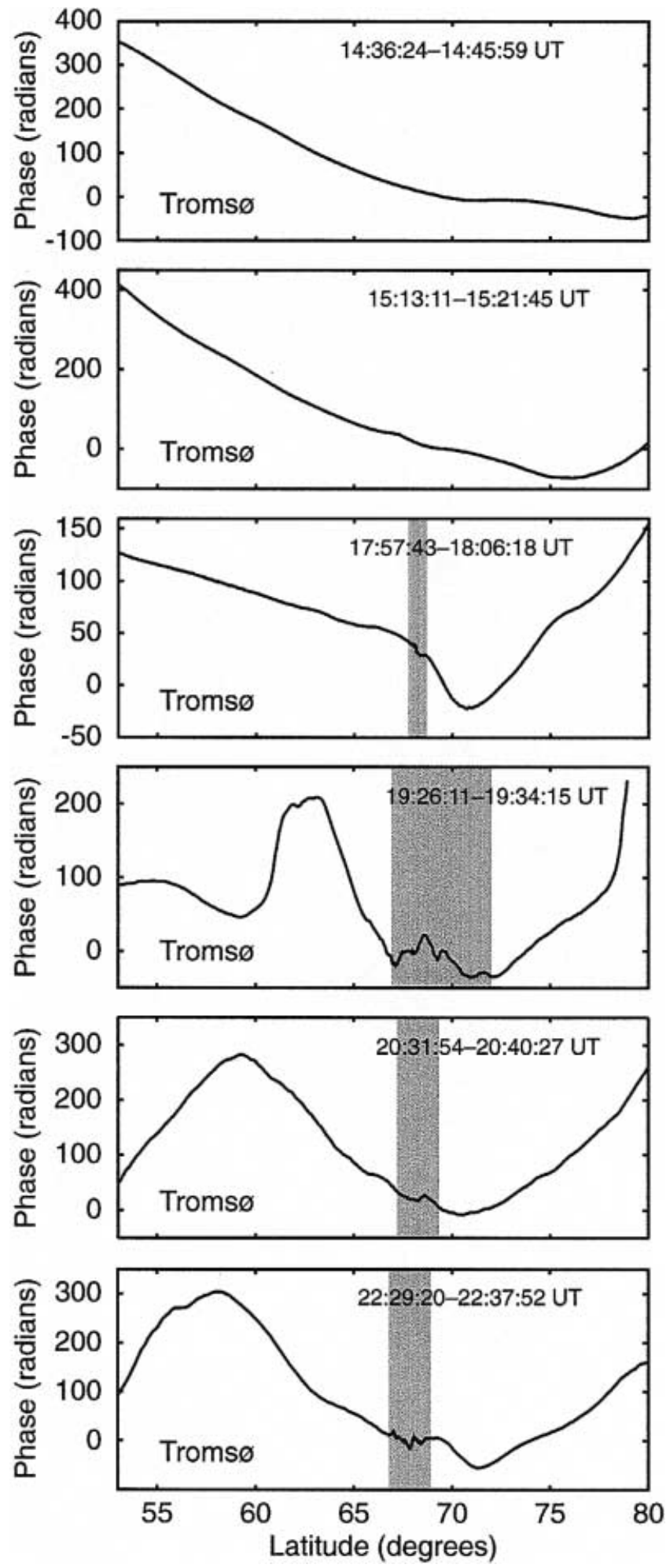

Fig. 2. The phase of the signal as a function of the geographic latitude of the satellite position for the six satellite passes in Fig. 1, observed at Troms $\varnothing$. The time intervals correspond to the latitude range $53-80^{\circ} \mathrm{N}$ of the satellite position and the grey stripes indicate the approximate latitude ranges where inhomogeneities are observed

heating power. The temporal behaviour of electron density, as seen by the EISCAT radar above Troms $\varnothing$ at 14:00-14:40 UT, is portrayed in Fig. 4. The results indicate a stationary and regular $\mathrm{F}$ layer within a large area. No specific features are seen which might be indicative of large-scale effects due to heating, which took place at 14:25-14:40 UT.

In order to account for the absence of visible manifestations of heating, we compared the frequency of the heating radio wave with the peak plasma frequency of the $F$ layer. Heating should be most effective in the ionosphere when the heating frequency is close to the plasma frequency. The plasma frequency $f_{e}$ is related to the electron concentration $N_{e}$ by

$f_{e}[\mathrm{~Hz}]=\sqrt{80.8 N_{e}\left[\mathrm{~m}^{-3}\right]}$.

To estimate the plasma frequency we used electron densities observed both by the tomographic method and by EISCAT. In Fig. 3 the maximum electron density within the heating cone was about $1.2-1.4 \times 10^{11} \mathrm{~m}^{-3}$. In Fig. 4 the $F$ layer peak height is at about $260 \mathrm{~km}$ altitude, and after 14:25 UT the peak electron density slightly decreases with time. At 14:30 UT the peak density is of the order of $1.2 \times 10^{11} \mathrm{~m}^{-3}$. There is a good agreement between these results and the corresponding critical frequency is $f_{0} \approx 3.1-3.4 \mathrm{MHz}$. Since these values are lower than the heating frequency $f_{h}=4.04 \mathrm{MHz}$, heating was probably inefficient at $\mathrm{F}$ region heights and caused no large-scale effect in the $\mathrm{F}$ region electron density.

If there are electron density gradients and strong electric fields in the ionosphere, generation of small-scale irregularities can be expected. The tomographic reconstruction shows no steep electron density gradients and, according to the EISCAT data, the electric fields were also weak (about $1-11 \mathrm{mV} / \mathrm{m}$ ). Indeed, no amplitude scintillation was observed at any of the three receiving sites. Hence we can conclude that neither large-scale nor small-scale artificial irregularities were generated in the $\mathrm{F}$ region ionosphere during the heating period 14:2514:40 UT.

Next time heating was carried out at 15:08-15:18 UT. Since the radio probing data from that time interval comes from a northward satellite pass, these measurements are unsuitable for tomographic analysis. The phase curves (not shown) contain no visible scintillation. This indicates the absence of large-scale irregularities during this period. No amplitude scintillations were measured at Kårvika and Nordkjosbotn. The amplitude variance curve at Troms $\varnothing$, shown in Fig. 5, has a single distinct peak. Fitting the model to the Troms $\varnothing$ curve gives $\alpha=35, \beta=8$ and $\varphi=57^{\circ}$. The Troms $\varnothing$ spot of measurement (as well as the expected spots of measurement with the same anisotropy parameters calculated for the other two sites) lie outside the heating cone. In conclusion, the behaviour of the phase and amplitude curves shows no large-scale irregularities and only local small-scale irregularities in the ionosphere, which have no obvious connection to heating.

A tomographic observation of electron density at 17:52-18:10 UT is portrayed in Fig. 6. This satellite pass covers the heating period 17:46-18:01 UT. A horizontal $F$ layer with a maximum electron density of 

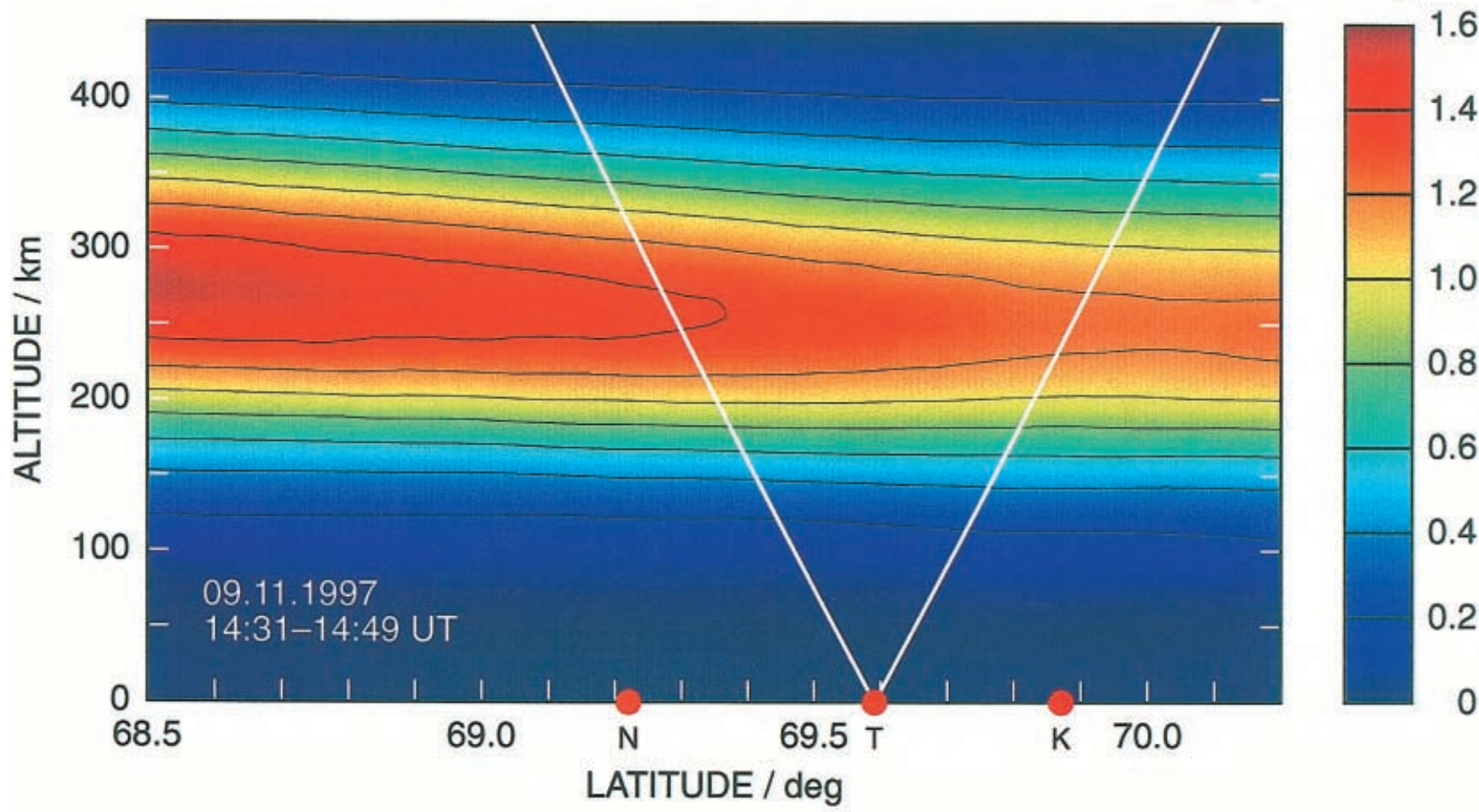

4

$\mathrm{N}_{\mathrm{e}}\left(10^{11} \mathrm{~m}^{-3}\right)$
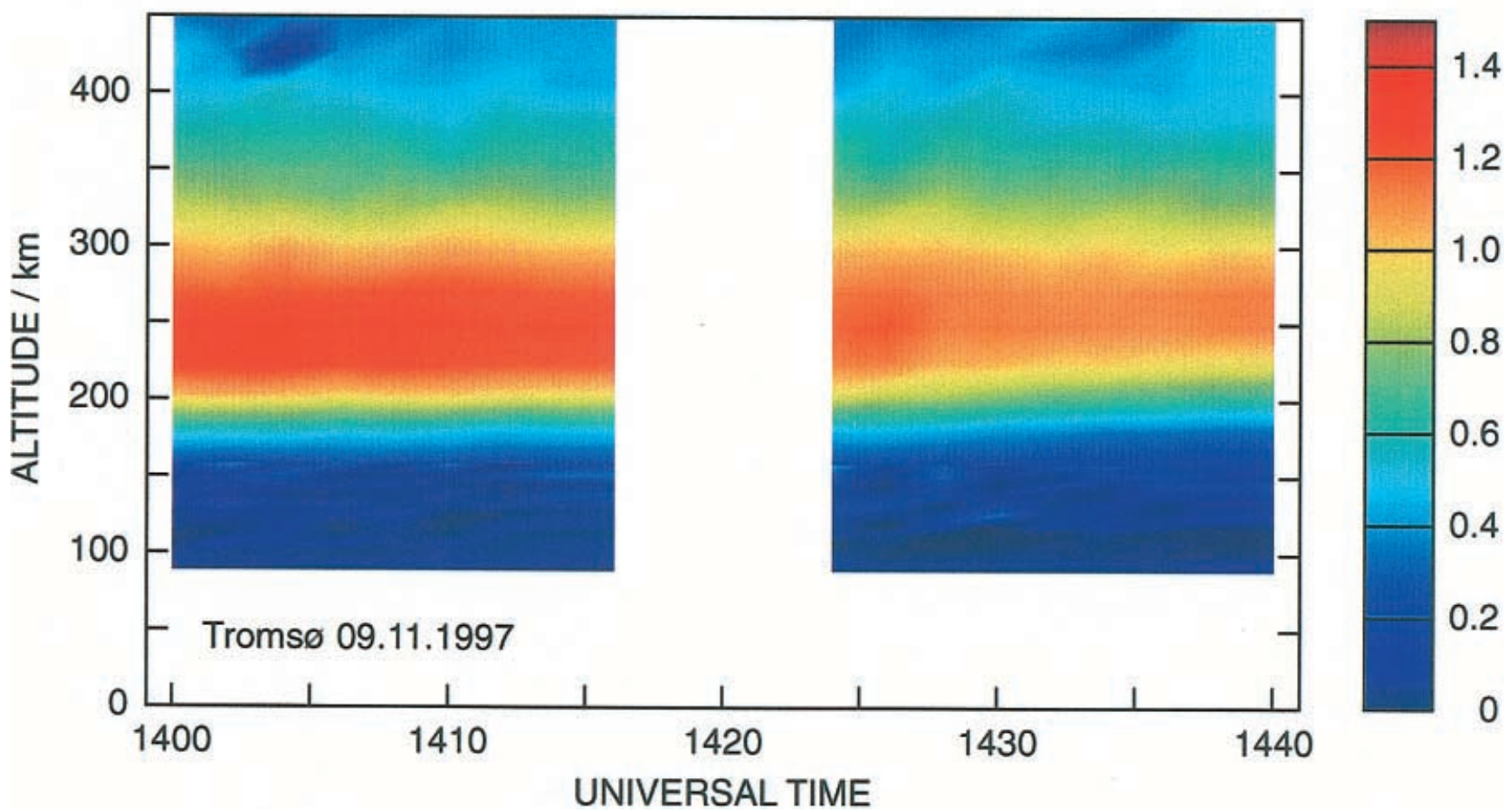

1.2

1.0

0.8

0.6

0.4

0.2

Fig. 3. Tomographic reconstruction of electron density in the vertical plane above the receiver chain at 14:31-14:49 UT on 9 November, 1997.

red dots and the $-3-\mathrm{dB}$ boundaries of the heating cone by white lines. The receiver sites Kårvika, Troms $\varnothing$ and Nordkjosbotn are indicated by

Fig. 4. EISCAT observation of electron density above Troms $\varnothing$ at 14:00-14:40 UT on 9 November, 1997 


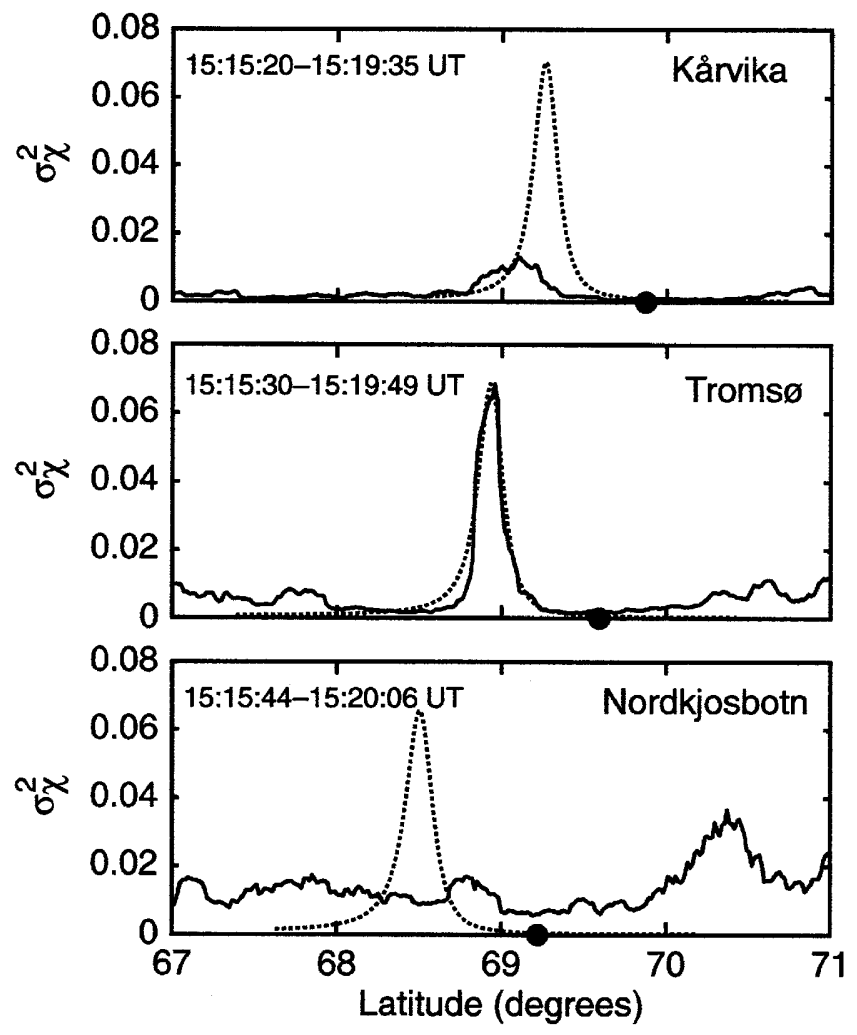

Fig. 5. The variance of logarithmic relative amplitude for the satellite pass at 15:15-15:20 UT on 9 November, 1997 for the three receiver sites (continuous lines). The horizontal axis indicates the latitude of the point where the ray crosses the $250-\mathrm{km}$ height and the time interval in each panel corresponds to a latitude range of $67-71^{\circ} \mathrm{N}$. The latitudes of the receiver sites are indicated by dots. The result of model fitting to the Troms $\emptyset$ data is shown by dashed line in the middle panel. In the top and bottom panels the dashed line indicates the expected peaks in the presence of a statistically homogeneous horizontal layer

$0.9 \times 10^{11} \mathrm{~m}^{-3}$ is seen in the south at a height of nearly $300 \mathrm{~km}$. In the north the electron density decreases down to $(0.3-0.4) \times 10^{11} \mathrm{~m}^{-3}$. The $\mathrm{F}$ layer is strongly tilted within the heating cone and slightly to the south of it. Within this region, two tilted plasma enhancements are encountered. The maximum plasma frequency is about $2.7 \mathrm{MHz}$ in the south and $2.3 \mathrm{MHz}$ within the heating cone. These values are lower than the daytime values discussed already and therefore one might assume that the heating effect is weak. However, a most remarkable fact is that the tilted region overlaps the heating cone, and this strongly suggests a heating effect. The shift of the tilted region southwards from the heating cone could be caused by transport of the plasma away from the heating site. This will be discussed in the Summary.

A steep density gradient, accompanied by a strong electric field, provides favourable conditions for generating small-scale irregularities. The amplitude variance curves at the three receiving sites are shown in Fig. 7. Distinct peaks are seen in Kårvika and Troms $\varnothing$ but no pronounced extremum is observed in Nordkjosbotn. The dashed white lines in Fig. 6 are projections of the rays corresponding to the observed maxima at Kårvika and Troms $\varnothing$. It is seen that these maxima are located close to the local gradients of electron density. The same irregularity model can be applied in fitting the Kårvika and Troms $\varnothing$ data, which means that the same generation mechanism may have produced the small-scale irregularities observed at Kårvika and Troms $\varnothing$. The fitted anisotropy parameters $\alpha=90, \beta=20$ and $\varphi=177^{\circ}$ seem to remain constant at least within the region between the Kårvika and Troms $\varnothing$ spots of measurement.

It is well known that strong ionospheric electric fields play an important role in the generation of small-scale irregularities at high latitudes. Therefore we suggest that a close correlation must exist between the orientation of the perpendicular anisotropy of the small-scale irregularities and the direction of the electric field. If so, then the perpendicular anisotropy would be oriented in the direction of the plasma flow in the ionospheric $\mathrm{F}$ region.

Figure 8 displays the direction of the perpendicular anisotropy $\varphi=177^{\circ}$ with error limits and the spots of observation for Kårvika and Troms $\varnothing$ as well as the location of the expected spot of observation for Nordkjosbotn at $250-\mathrm{km}$ height. Also the location of the heating cone is shown in the figure. The Kårvika spot of measurement lies well within the heating cone. Assuming that the heated plasma flows from the heated region southwards in the direction of the perpendicular anisotropy, it is possible that the heating effect is still visible at at the Troms $\varnothing$ spot of measurement. The absence of a maximum at Nordkjosbotn may be due to the fact that the expected spot of measurement is the most remote one. At this distance the plasma irregularities could already have decayed.

During the next heating interval at 19:16-19:31 UT the satellite data were obtained from a northward pass. Although these data are not well suited for tomography, the phase curves still give information on the large-scale structures around the heating facility. The phase curves are plotted in Fig. 9. In addition to smooth variations which are visible in all three curves, fine structures, indicated by the grey stripe, are observed at Kårvika. The amplitude variance curves at the three receiving sites are shown in Fig. 10. A distinct peak is seen in Kårvika but no clear peak is created at Troms $\varnothing$ and Nordkjosbotn. The Kårvika peak can be properly reproduced by the model parameters $\alpha=35, \beta=7$, $\varphi=76^{\circ}$. The direction of perpendicular anisotropy indicating the possible direction of the plasma flow is shown in Fig. 11. Assuming again that the plasma flows in the direction of the perpendicular anisotropy, the expected path of the heated plasma cloud passes through the Kårvika spot of measurement but lies to the north of the other two spots. Thus irregularities due to heating might be observed at Kårvika but not at Troms $\varnothing$ and Nordkjosbotn. Therefore the observation is in agreement with the assumption that the irregularities are of artificial origin.

Tomographic reconstruction of the phase data from the satellite pass at 20:26-20:44 UT is shown in Fig. 12. This figure is from an interval between two heating periods and it indicates that the ionosphere has relaxed to its regular condition. The $\mathrm{F}$ layer is nearly horizontal 


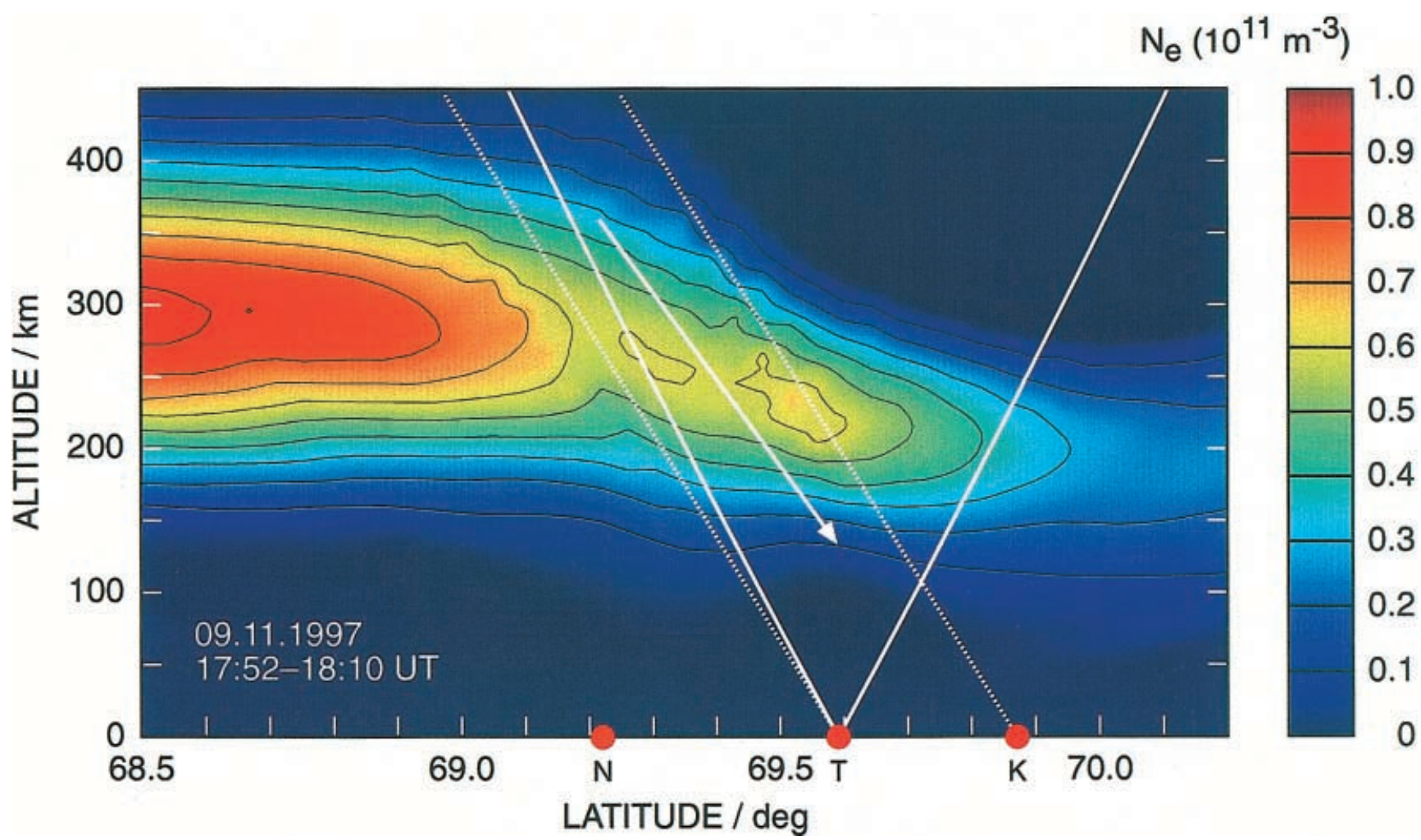

Fig. 6. Same as Fig. 3 at 17:52-18:10 UT on 9 November, 1997. The white dashed lines are projections to the image plane for the rays corresponding to the peaks in $\sigma_{\chi}^{2}$ and the white arrow is the projection of the geomagnetic field direction to the image plane
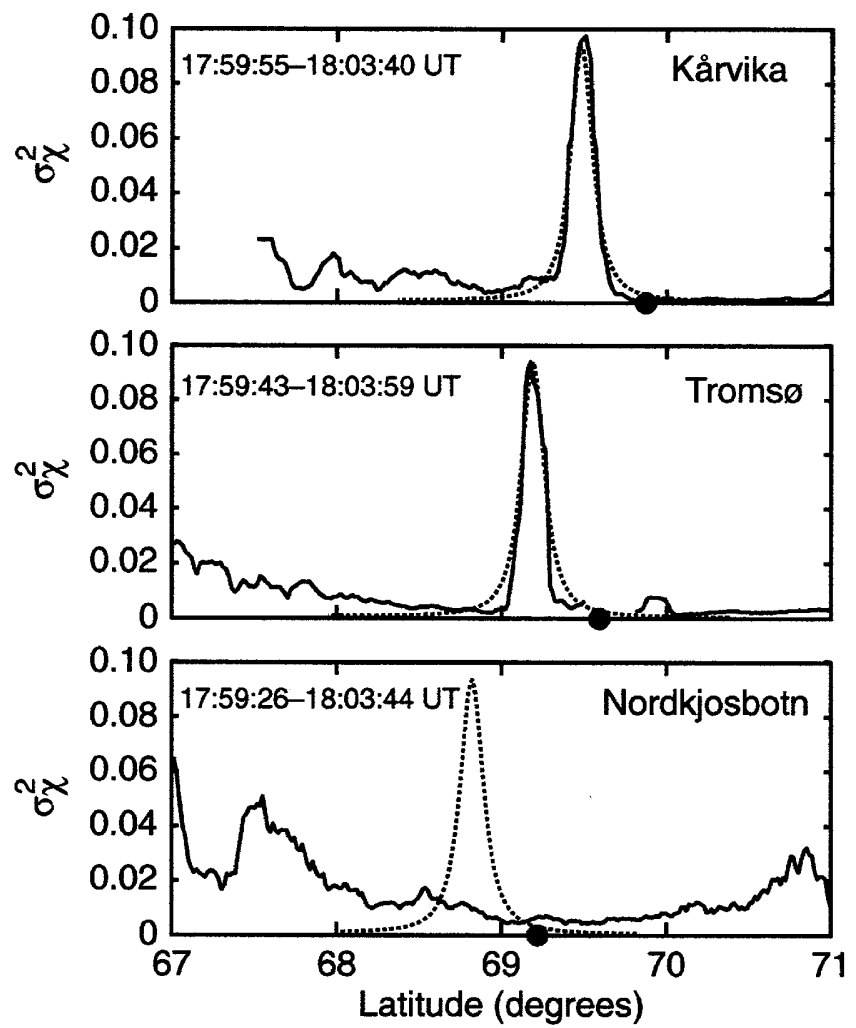

Fig. 7. Same as Fig. 5 for the satellite pass at 17:59-18:04 UT on 9 November, 1997

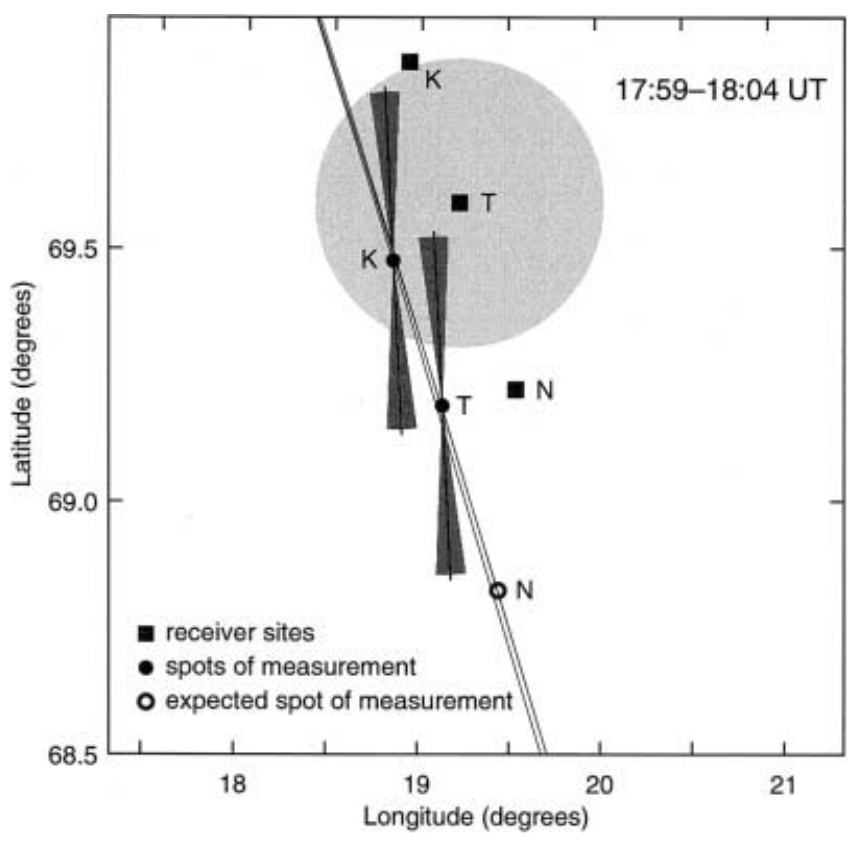

Fig. 8. The positions of the receiver sites together with the observed and expected spots of measurement for the satellite pass at 17:5918:04 UT on 9 November, 1997. The thick lines surrounded by shaded cones indicate the direction of the perpendicular anisotropy and error limits, respectively, and the thin lines passing through the measurement spots are projections of satellite paths. The grey circle shows the size of the heating cone at a height of $250 \mathrm{~km}$ 


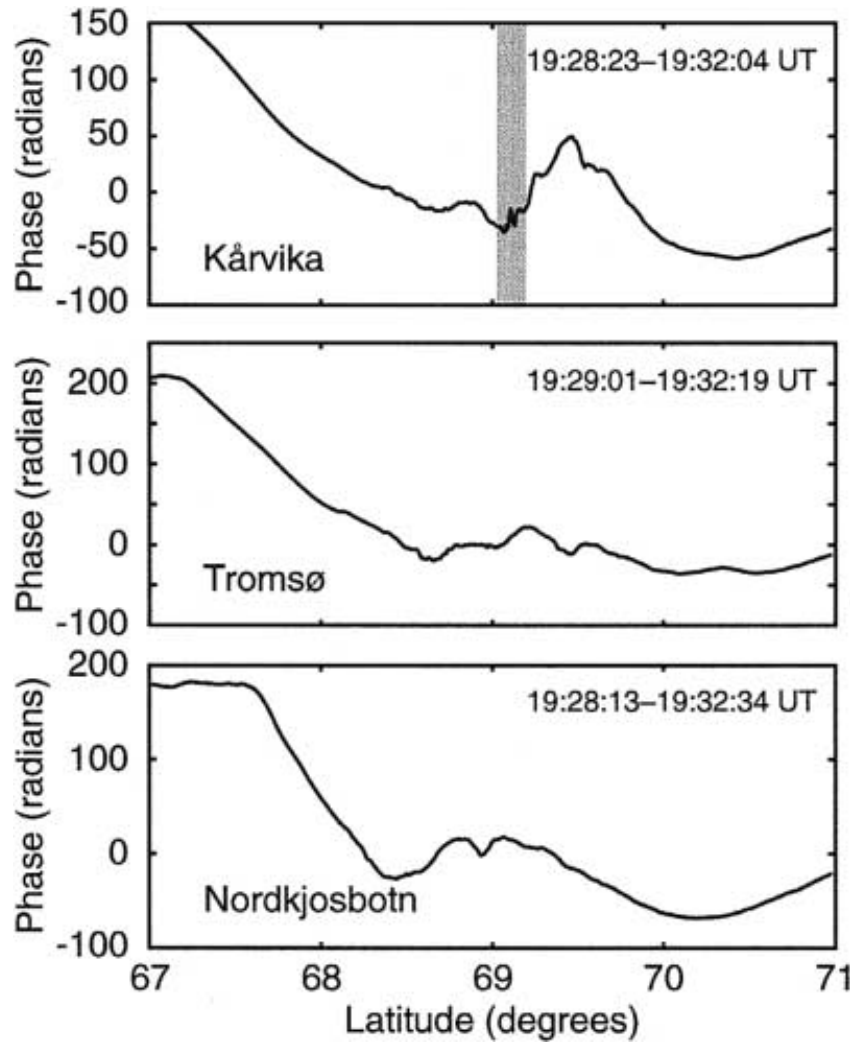

Fig. 9. Same as Fig. 2 for the three receiver sites during the satellite pass at 19:28-19:33 UT on 9 November, 1997

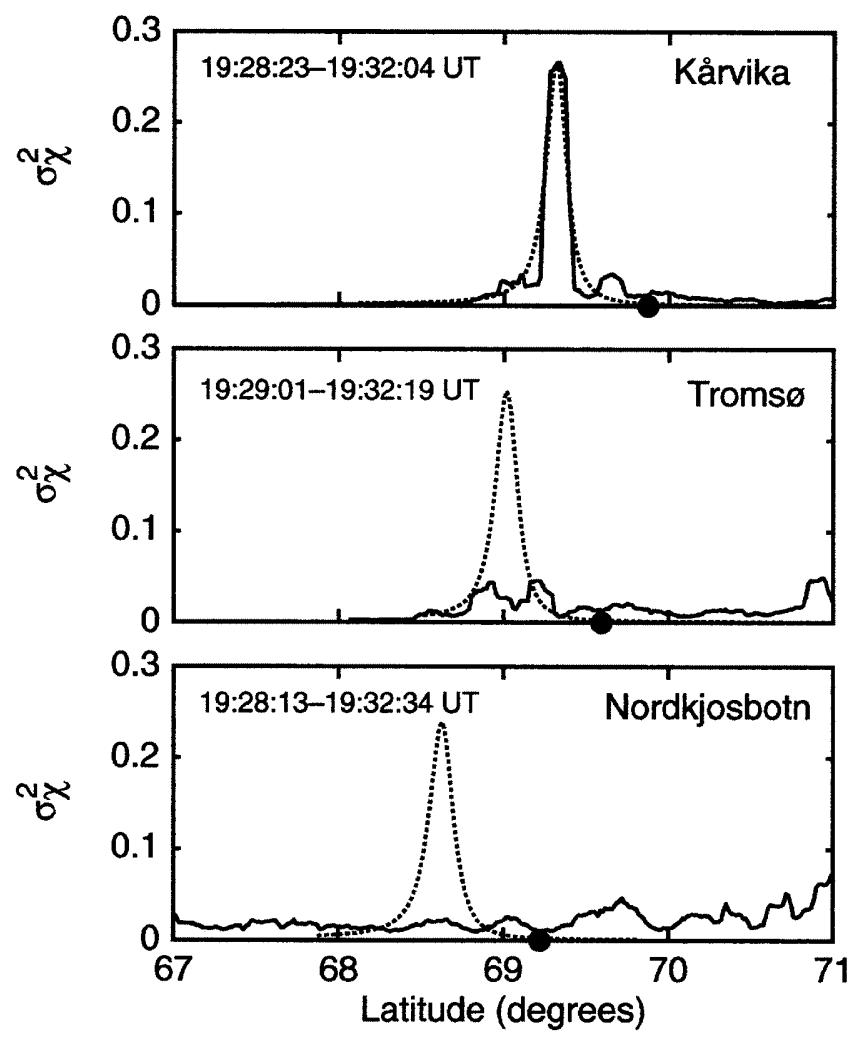

Fig. 10. Same as Fig. 5 for the satellite pass at 19:28-19:33 UT on 9 November, 1997. The dashed line in the top panel is due to fitting and in the other two panels it indicates the expected peaks

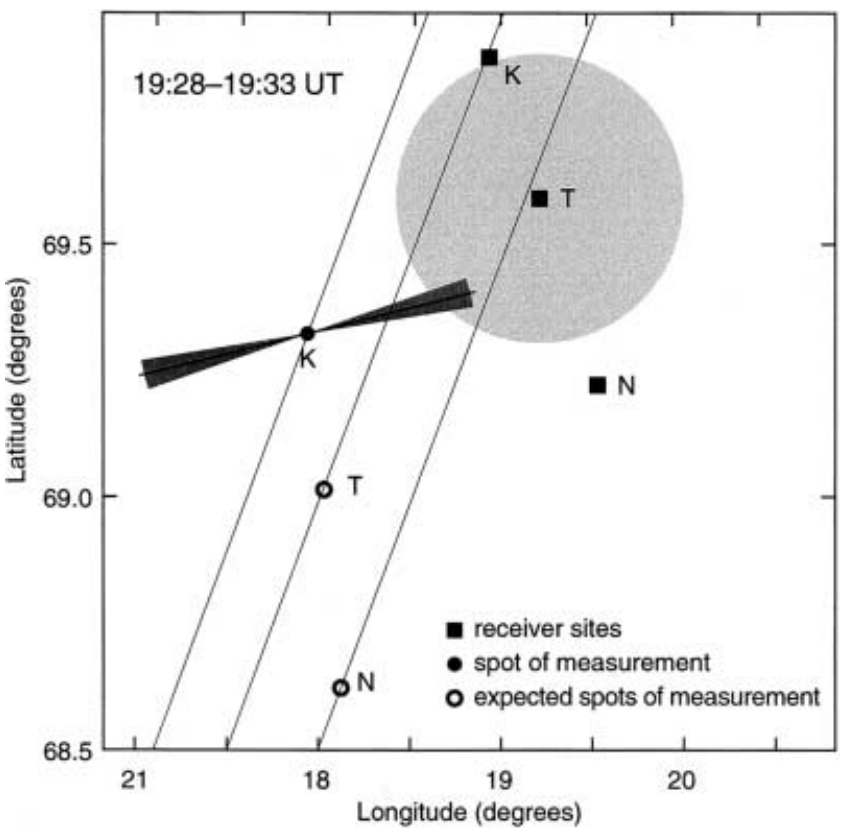

Fig. 11. Same as Fig. 8 for the satellite pass at 19:28-19:33 UT on 9 November, 1997

and only slightly structured. No strong tilt and decrease in electron density similar to that in Fig. 6 is visible in this case. Unfortunately the amplitude data were affected by noise and therefore were unsuitable for investigating the small-scale irregularities.

The next heating interval was at 22:18-22:33 UT. Both satellite and EISCAT data were available for this period and enhanced phase disturbances as well as amplitude scintillation were observed.

The tomographic reconstruction of electron density from the closest satellite pass at 22:23-22:40 UT is plotted in Fig. 13. It shows again a behaviour very similar to that in Fig. 6; i.e. a decreased electron density within the heating cone and a steep tilt extending from $\mathrm{F}$ region in the south to $\mathrm{E}$ region altitudes in the north. In this case the tilt is more clearly restricted within the heating cone than in Fig. 6. Southward of the heating region the $\mathrm{F}$ layer is nearly horizontal with its peak height close to $290 \mathrm{~km}$ and a maximum electron density of approximately $1.7 \times 10^{11} \mathrm{~m}^{-3}$. Within the heating cone the electron density decreases to $1.2 \times 10^{11} \mathrm{~m}^{-3}$ or below. There are also tilted plasma enhancements much like in Fig. 6 and they seem to have field-aligned orientation.

In order to investigate the temporal variation of electron density around the heating period, three consecutive EISCAT scans are shown in Fig. 14, where electron density in every beam direction is indicated by colour code within a beam-oriented stripe. The start time of each measurement is shown at the respective beam position. The heating begins at 22:18 UT during the northward scan in the top panel, which indicates a fairly horizontal $\mathrm{F}$ layer with its peak close to the height of $250 \mathrm{~km}$. During the following southward scan the layer has changed: much in agreement with the tomo- 
12

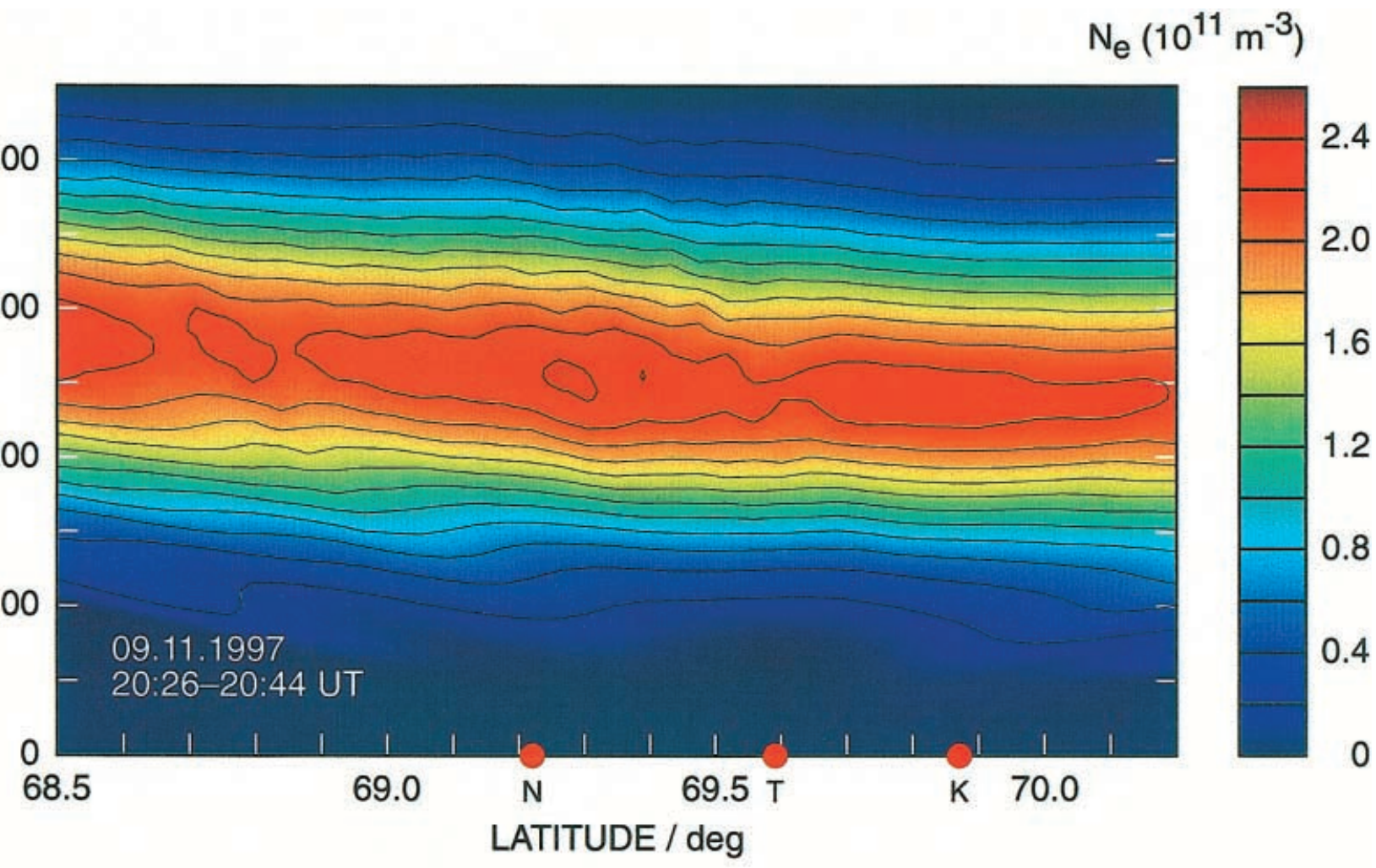

13

$$
\mathrm{N}_{\mathrm{e}}\left(10^{11} \mathrm{~m}^{-3}\right)
$$
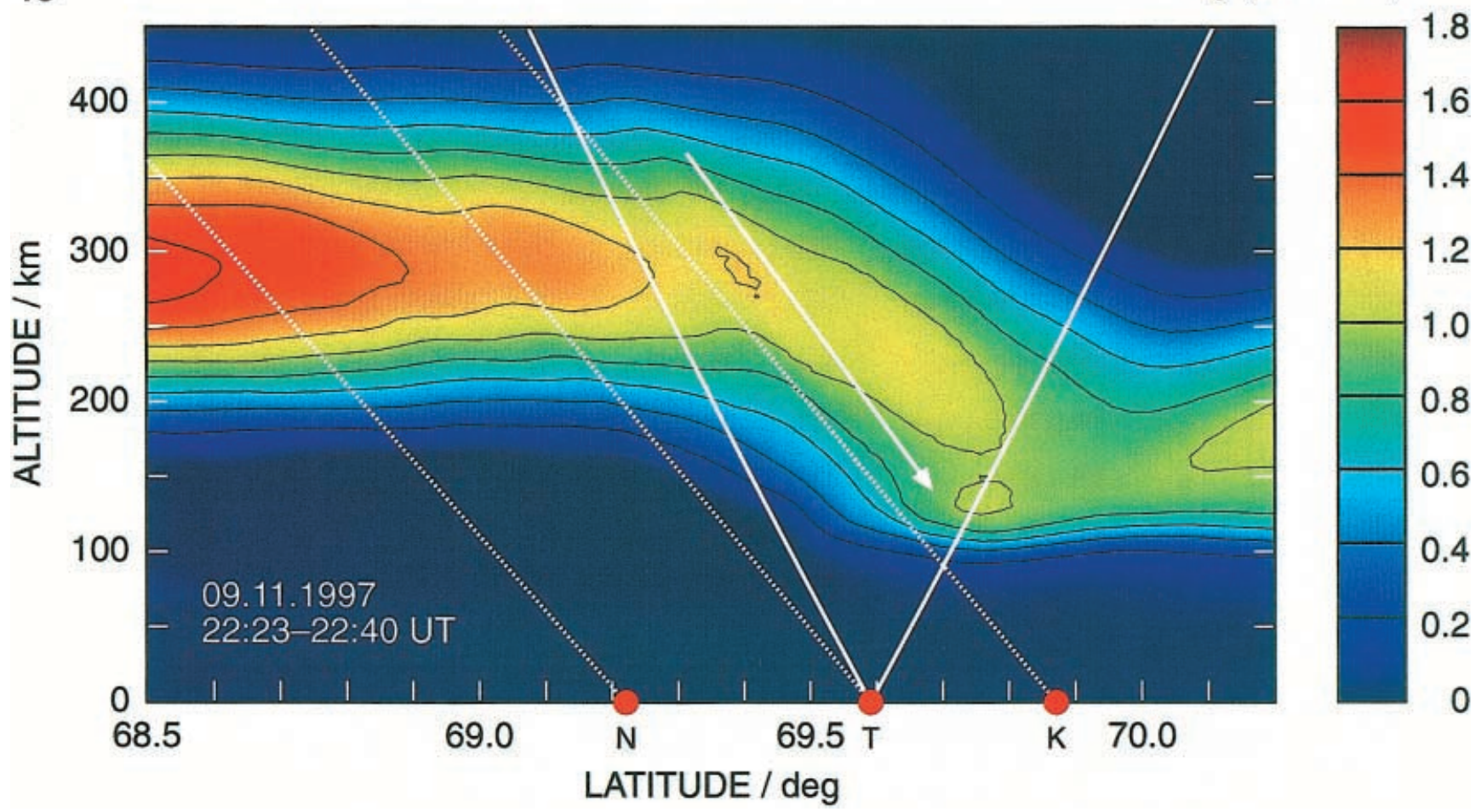

Fig. 12. Same as Fig. 3 for the satellite pass at 20:26-20:44 UT on 9 November, 1997

Fig. 13. Same as Fig. 3 for the satellite pass at 22:23-22:40 UT on 9 November, 1997

graphic observation the peak height is close to $300 \mathrm{~km}$ in the south and the layer is weak close to the heater site. No heating is present during the northward scan in the bottom panel. Then the $\mathrm{F}$ region around the heater site is observed to recover but the tilt of the layer is still clearly visible. The EISCAT measurements reveal great 

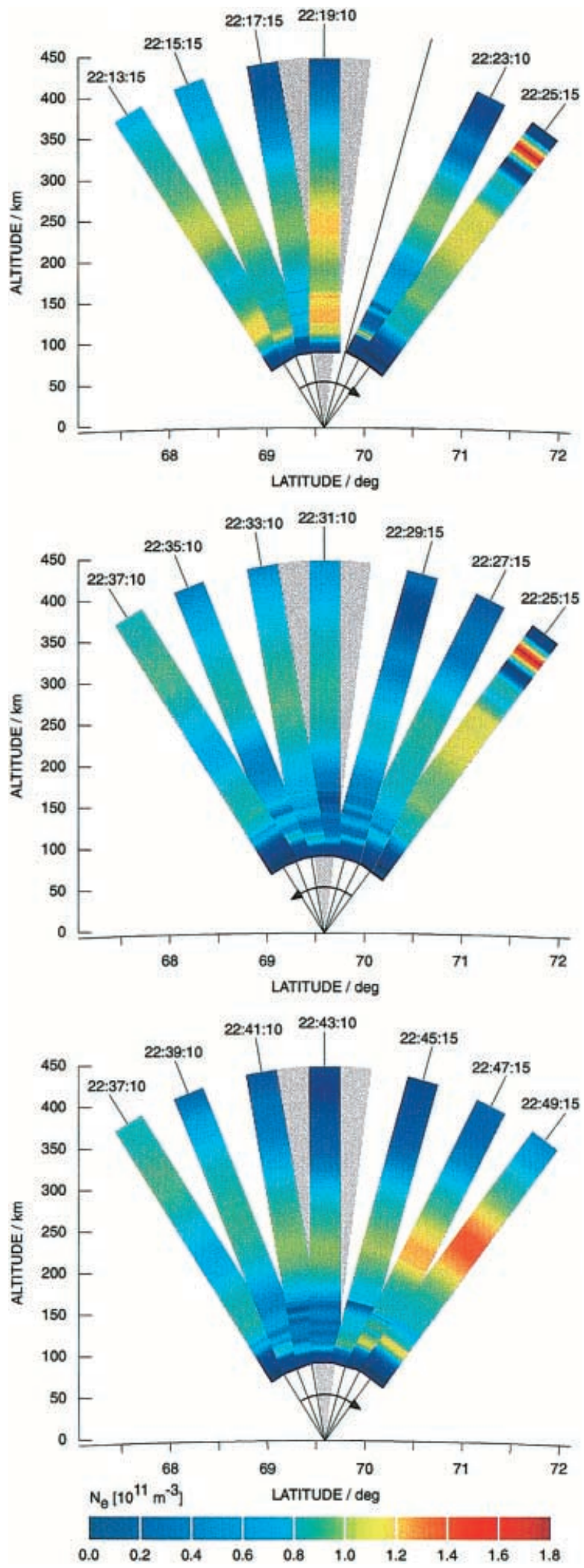

Fig. 14. Electron density from three EISCAT scans around the heating period 22:18-22:33 UT on 9 November, 1997. The start time of each measurement is shown at the respective beam direction and the scan direction is indicated by an arrow temporal variations in the $\mathrm{F}$ region which may affect the reliability of the tomographic reconstruction. Nevertheless, the same main features can be found in both observations although the tomographic reconstruction gives somewhat higher electron densities.

At the start time of heating the peak electron density given by the EISCAT radar is about $(1-1.2) \times 10^{11} \mathrm{~m}^{-3}$ within the heating cone. This corresponds to a critical frequency $f_{0} \approx 2.8-3.1 \mathrm{MHz}$, which was the same or slightly smaller than in Figs. 3 and 4, when no heating effect was observed in the $\mathrm{F}$ region.

The amplitude variances are shown in Fig. 15, where all three curves contain distinct maxima. Projections of the corresponding rays are plotted in Fig. 13 by dashed white lines. The positions of the peaks are properly reproduced by fitting the model with $\alpha=28, \beta=5$ and $\varphi=76^{\circ}$. The best fit is obtained at Troms $\varnothing$. The fact that the peak values at Kårvika and Nordkjosbotn do not match can be explained by assuming horizontal variations in the intensity of density fluctuations.

At 22:27-22:39 UT, strong electric fields of 20$70 \mathrm{mV} / \mathrm{m}$ were observed by EISCAT within the latitude range $68.3-70.6^{\circ} \mathrm{N}$ at altitudes of $250-260 \mathrm{~km}$. At 22:33-22:35 UT, when peaks were observed in the variance curves, the EISCAT tristatic volume lay at $260-\mathrm{km}$ height close to the three spots of measurement. This is portrayed in Fig. 16, where the orientation of perpendicular anisotropy is compared with the direction of $\mathrm{F}$ region plasma flow. The EISCAT measurement

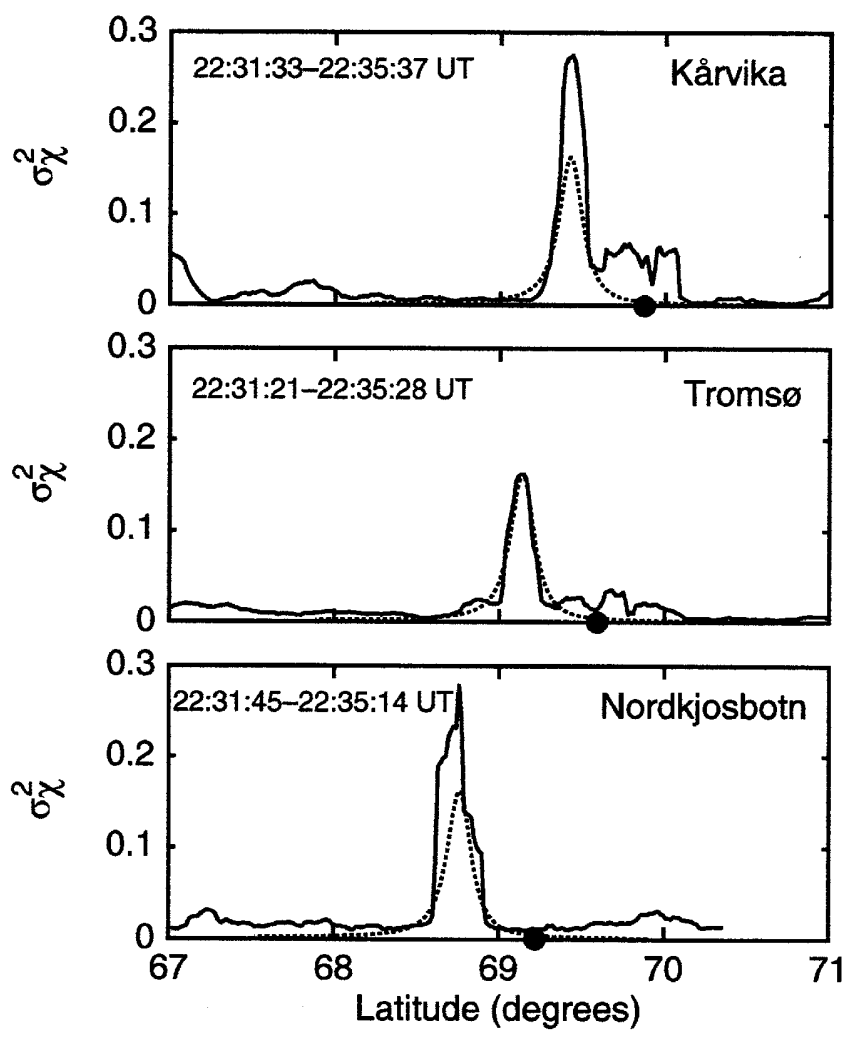

Fig. 15. Same as Fig. 5 for the satellite pass at 22:31-22:36 UT on 9 November, 1997. The dashed line in the middle panel is due to fitting and in the other two panels it indicates the expected peaks 


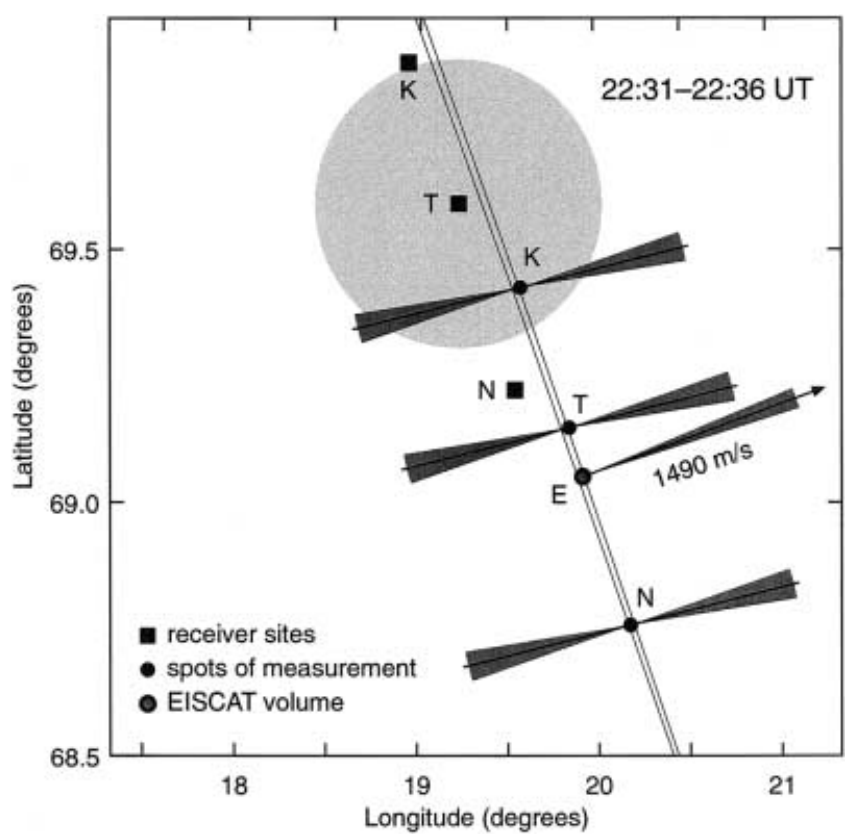

Fig. 16. Same as Fig. 8 for the satellite pass at 22:31-22:36 UT on 9 November, 1997. The ion velocity vector observed by the EISCAT radar is also shown together with a cone indicating the error in the flow direction

point is close to the Troms $\varnothing$ spot of measurement so that these observations come nearly from the same location. The figure shows that the directions of perpendicular anisotropy and plasma flow agree within error limits and the flow direction is nearly perpendicular to the tomographic image plane. While the Kårvika spot of measurement lies with the heating cone, the drift direction does not allow the heated plasma cloud to reach the Troms $\varnothing$ and Nordkjosbotn spots of measurement.

The intensity of the observed small-scale irregularities can be estimated by using the integral intensity $\left(C_{S} L\right)^{1 / 2}$ which is often employed in modelling the natural small-scale irregularities (Fremouw and Secan, 1984). In this definition $L$ is the thickness of the layer of irregularities and

$C_{S}=8 \pi^{3 / 2} \frac{\Gamma(p / 2)\left(2 \pi / L_{0}\right)^{p-3}}{\Gamma[(p-3) / 2]} \sigma_{N}^{2}$,

where $L_{0}$ is the scale length of the irregularities. The integral intensity can be calculated from experimental data using Eq. (2). Within a region of constant variance of density fluctuations, Eq. (2) can be written as

$$
\begin{aligned}
\sigma_{\chi}^{2}= & \sigma_{N}^{2} \cdot \frac{\lambda^{2} r_{e}^{2} \alpha \beta L_{0}^{3-p} \pi^{(p-1) / 2}}{\Gamma[(p-3) / 2] \sin (\pi p / 4)} \\
& \times \int_{z_{L}}^{z_{U}} f\left[R_{F}(z), \alpha, \beta, \Psi, p, \Theta(z)\right] \mathrm{d} z .
\end{aligned}
$$

Solving $\sigma_{N}^{2}$ from this equation and inserting in Eq. (4) gives

$$
\begin{aligned}
\sqrt{C_{S} L}= & \frac{2^{p / 2} \pi^{(p-2) / 4}}{\lambda r_{e}} \\
& \times \sqrt{\frac{\Gamma(p / 2) \sin (\pi p / 4)\left(\sigma_{\chi}^{2}\right)_{\max }}{\alpha \beta \int_{z_{L}}^{z_{U}} f\left[R_{F}(z), \alpha, \beta, \Psi, p, \Theta(z)\right] \mathrm{d} z}} .
\end{aligned}
$$

An experimental estimate for the integral intensity is obtained by inserting the observed peak value $\left(\sigma_{\chi}^{2}\right)_{\max }$ in Eq. (6).

The observed integral intensities for the above examples are plotted in Fig. 17 as a function of time. It is seen that, in general, the intensity increases towards evening. This effect can be due to increased efficiency of heating. The observed values are of the same order of magnitude as the integrated intensities of natural irregularities predicted by the WBMOD model (Fremouw et al., 1985).

\section{Summary}

The examples shown demonstrate different situations which may arise when the ionospheric $F$ region is heated by powerful radio waves. Sometimes heating shows no effect on the ionosphere, but at other times strong changes are observed which seem to be of artificial origin. Finally, there are disturbances which could be due to heating but might be due to natural causes as well. Since plasma irregularities are known to be generated in the ionosphere both spontaneously and by means of heating, it is understandable that difficulties may arise in distinguishing between the two agents.

No heating effects were observed during the daytime heating period at 14:25-14:40 UT. Since the peak electron density did not exceed $1.4 \times 10^{11} \mathrm{~m}^{-3}$, the critical frequency of the layer was clearly lower than the heating frequency. The second daytime heating period at 15:08-15:18 UT also shows no large-scale effect of

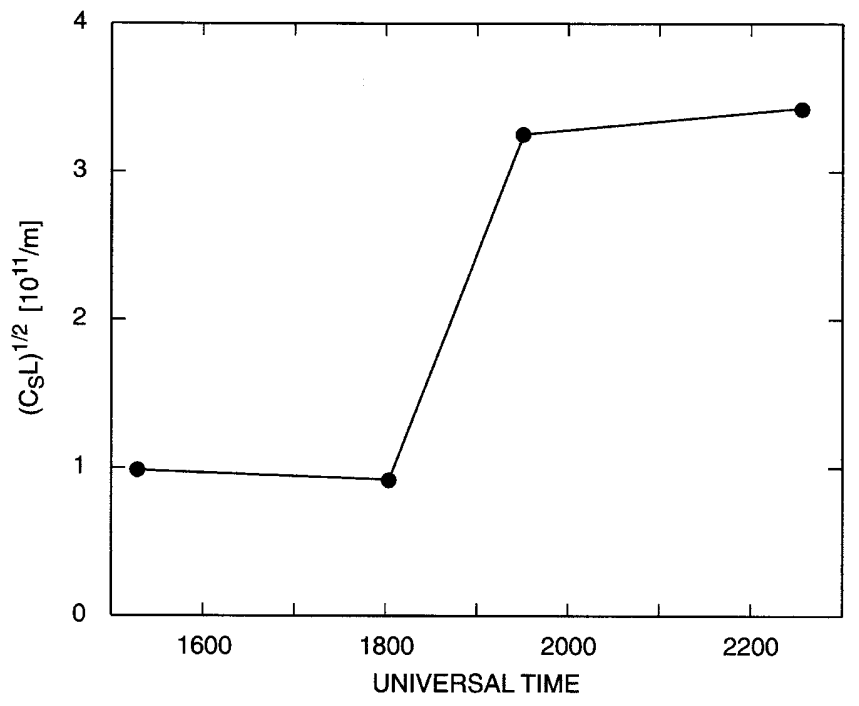

Fig. 17. The integral intensity of observed irregularities (dots) as a function of universal time on 9 November, 1997 
heating. Although small-scale irregularities are observed at a single site, they are probably due to natural reasons.

Ionospheric disturbances were observed during the other three heating intervals. The $\mathrm{F}$ region was greatly deformed during the heating periods at 17:46-18:01 UT and 22:18-22:30 UT (from the period 19:16-19:31 UT similar observations were not available). A reduction of electron density and a steep tilt of the layer, closely overlapping the heating cone, was observed in both cases. Such cavities have been reported e.g. by Duncan et al. (1988), Wright et al. (1988), Bernhardt et al. (1989) and Hansen et al. (1990, 1992). Tomographic measurements allowed us to map the modified region for the first time. This modified region in one of the examples extended somewhat to the south of the heating cone. Local enhancements were also observed within this region. These irregularities exceeded $10 \mathrm{~km}$ in size and they were more or less oriented along the geomagnetic field, obviously due to field-aligned diffusion. These results agree with previous investigations, which also report depleted electron density with enhancements in the heated ionospheric $\mathrm{F}$ region with field-aligned structures of observed irregularities (Robinson, 1989; Stubbe, 1996). Hence it seems likely that these deformations are caused by heating. This interpretation is further supported by the fact that a regular horizontal $\mathrm{F}$ layer was observed between the two heating periods.

Small-scale irregularities with scale lengths of several hundreds of metres were also observed during the three evening-time heating periods. These were elongated along the magnetic field and also in some perpendicular direction. In one of the cases (22:18-22:30 UT) irregularities were observed at all three sites and it was possible to show that the perpendicular anisotropy was oriented in the direction of the $\mathbf{E} \times \mathbf{B}$ drift. Only the most northern spot of measurement lay within the heating cone, however, and the plasma drift was not directed towards the other two spots. This seems to support a natural generation of the small-scale irregularities by means of the strong electric field. One might suggest that field-aligned diffusion has a role in shifting the irregularities towards lower latitudes but, considering the local magnetic inclination and the latitude of the southernmost spot of measurement, this does not look like a plausible explanation.

During the heating period 17:46-18:01 UT, smallscale irregularities were observed in the two northernmost spots of measurement. The Kårvika spot lay within the heating cone and the Troms $\varnothing$ spot to the south of it, within the expected drift path of the heated plasma cloud. The expected Nordkjosbotn spot lay also within the expected drift path, but it was located further away from the heating cone. This observation is in agreement with the assumption that the observed irregularities were generated within the heating cone, drifted southwards to the Troms $\varnothing$ spot of measurement but decayed before they could reach the Nordkjosbotn spot. The heating period 19:16-19:31 UT is slightly different; then small-scale irregularities were observed only by the Kårvika receiver and the corresponding spot of measurements lay nicely within the expected path of the heated plasma cloud, while the other two expected spots were clearly outside of the path. This case is also in agreement with the assumption that the irregularities were due to heating.

There is still one consequence of the drift directions during two of the evening-time heating periods. At 22:18-22:30 UT, when the drift is approximately perpendicular to the tomographic image plane, the tilt of the ionosphere lies well within the heating cone. On the other hand, at 17:46-18:01 UT the tilt extends southwards of the heating cone as would be expected in the presence of southward plasma drift. Hence the latter observation supports the interpretation that the drift is southward in this case and the small-scale irregularities observed at Troms $\varnothing$ have indeed drifted away from the heating cone.

This work demonstrates the possibilities of combined incoherent scatter, tomographic and scintillation measurements in connection with ionospheric heating. At the present, such observations are available only from a single campaign and therefore the data set is still quite limited. Nevertheless it seems clear that heating-induced large-scale variations can be observed by the tomographic method and the anisotropy parameters, especially the perpendicular anisotropy, can be determined from amplitude scintillation. The latter gives us information on the direction of the ionospheric plasma drift. Whether the observed small-scale irregularities are due to heating or of natural origin is a more difficult question but, by combining observations from different sites and methods, some conclusions can be drawn even on this topic.

Acknowledgements. The authors are grateful to T.L. Hansen and A. Mortensen for their help in arranging the Kåvika receiver site as well as to A.P. van Eyken for the antenna scanning software and to R. Kuula for making the analysis of the incoherent scatter data. The tomographic package was created at the Sodankylä Geophysical Observatory by M. Lehtinen, M. Markkanen and coworkers. This work was supported by the Academy of Finland and by the Russian Foundation of Fundamental Research grant 1 98-0565049. The EISCAT measurements were made with special programme time granted to users outside the Association. EISCAT is an International Association supported by Finland (SA), France (CNRS), the Federal Republic of Germany (MPG), Japan (NIPR), Norway (NFR), Sweden (NFR) and the United Kingdom (PPARC).

Topical Editor M. Lester thanks a referee for his help in evaluating this paper.

\section{References}

Basu, S., S. Basu, P. Stubbe, H. Kopka, and J. Waaramaa, Daytime scintillations induced by high-power HF waves at Troms $\varnothing$, Norway, J. Geophys. Res., 92, 11 149-11 157, 1987.

Bernhardt, P. A., C. A. Tepley, and L. M. Duncan, Airglow enhancements associated with plasma cavities formed during ionospheric heating experiments, J. Geophys. Res., 94, 90719092, 1989.

Costa, E., S. Basu, R. C. Livingston, and P. Stubbe, Multiple baseline measurements of ionospheric scintillation induced by high-power HF waves, Radio Sci., 32, 191-197, 1997.

Duncan, L. M., J. P. Sheerin, and R. A. Behnke, Observations of ionospheric cavities generated by high-power radio waves, Phys. Rev. Lett., 61, 239-242, 1988. 
E. D. Tereshchenko et al.: Irregular structures of the F layer at high latitudes during ionospheric heating

Fremouw, E. J., and J. A. Secan, Modelling and scientific application of scintillation results, Radio Sci., 19, 687-694, 1984.

Fremouw, E. J., J. A. Secan, and J. M. Lansinger, Spectral behaviour of phase scintillation in the nighttime auroral region, Radio Sci., 20, 923-933, 1985.

Hansen, J. D., G. J. Morales, L. M. Duncan, J. E. Maggs, and G. Dimonte, Large-scale ionospheric modifications produced by nonlinear refractions of an hf wave, Phys. Rev. Lett., 65, 32853288, 1990.

Hansen, J. D., G. J. Morales, L. M. Duncan, and G. Dimonte, Large-scale HF-induced ionospheric modifications: experiments, J. Geophys. Res., 97, 113-122, 1992.

Markkanen, M., M. Lehtinen, P. Henelius, E. Vilenius, T. Nygrén, E. D. Tereshchenko, and B. Z. Khudukon, A Bayesian approach to satellite radio tomography with applications in the Scandinavian sector, Ann. Geophysicae, 13, 1277-1287, 1995.

Nygrén, T., M. Markkanen, M. Lehtinen, E. D. Tereshchenko, and B. Z. Khudukon, Stochastic inversion in ionospheric radiotomography, Radio Sci., 32, 2359-2372, 1997.
Robinson, T. R., The heating of the high latitude ionosphere by high power radio waves, Phys. Rep., 179, 79-209, 1989.

Stubbe, P., Review of ionospheric modification experiments at Troms $\varnothing$, J. Atmos. Terr. Phys., 58, 349-368, 1996.

Tereshchenko, E. D., B. Z. Khudukon, M. T. Rietveld, and A. Brekke, Spatial structure of auroral day-time ionospheric electron density irregularities generated by a powerful HFwave, Ann. Geophysicae, 16, 812-820, 1998.

Tereshchenko, E. D., B. Z. Khudukon, M. O. Kozlova, and T. Nygrén, Anisotropy of ionospheric irregularities determined from the amplitude of satellite signals at a single receiver, Ann. Geophysicae, 17, 508-518, 1999.

Tereshchenko, E. D., B. Z. Khudukon, M. O. Kozlova, O. V. Evstafiev, T. Nygrén, M. T. Rietveld, and A. Brekke, Comparison of the orientation of small scale electron density irregularities and $\mathrm{F}$ region plasma flow direction, Ann. Geophysicae (in press) 2000.

Wright, J. W., H. Kopka, and P. Stubbe, A large-scale ionospheric depletion by intense radio wave heating, Geophys. Res. Lett., 15, 1531-1533, 1988. 